\title{
Emotional Maturity and Academic Achievement among Adolescent Students: A Review of Studies
}

\author{
Manoj Kumar ${ }^{1}$, Dr. Rishi Mishra ${ }^{2 *}$
}

\section{ABSTRACT}

Emotional maturity refers to our capability to understand and manage our emotions. When we are faced with a complex situation, our level of emotional maturity is one of the biggest factors in determining our ability to cope. Adolescence is a time of transition from childhood to being an independent adult; it is a period of life characterized by change and by moving away from one's family and towards one's peers. Education is the process of development from child to Adolescence or adulthood. The School education particularly high School education plays an important role in personal and professional success. But during this stage of life many factors influence, the process of education an especially academic accomplishment that is why the present study has been conducted to investigate the relationship of emotional maturity in the academic achievement among Adolescence students. The findings of the present investigation reveal that there is a positive correlation between emotional maturity and academic achievement among Adolescence students. Thus, emotional maturity plays important role in the academic achievement of students.

Keywords: Emotional Maturity, Academic Achievement \& Adolescence.

Children are the future citizens of a country. Children are the greatest resource of the nation. The children are required to adopt certain behavioral standards for the integration of the society. These standards vary somewhat from culture to culture and society to society. They are the key regulators that guide the child towards the social and anti-social behavior. Adolescence is one of the important periods of life. It is age in which adolescence face a many problems. Family also plays an important role in the personality development of adolescence. Adolescent period is associated with notable changes in mood sometimes known as mood swings. Cognitive, emotional and attitudinal changes which are characteristic of adolescence, often take place

\footnotetext{
${ }^{1}$ Assistant Professor and Coordinator (Behavioral Science), Amity Institute of Psychology and Allied Sciences, Amity University, Noida, U.P, India.

${ }^{2}$ Visiting Faculty, Amity Institute of Psychology and Allied Sciences, Amity University, Noida, U.P, India.

*Responding Author

(C) 2016 I M Kumar, R Mishra; licensee IJIP. This is an Open Access Research distributed under the terms of the Creative Commons Attribution License (http://creativecommons.org/licenses/by/2.0), which permits unrestricted use, distribution, and reproduction in any Medium, provided the original work is properly cited.
} 


\section{Emotional Maturity and Academic Achievement among Adolescent Students: A Review of Studies}

during this period, and this can be a cause of conflict, stress and depression and positive personality development on the other. Adolescence required proper guidance at this crucial phase of life for enhancing their positive self-concept, enriching their knowledge and skills in decisionmaking, conflict resolution and management of emotions. Researchers have proved that this is the most important period of one's life and during this time the vital foundation is laid for optimum development of an individual personality.

\section{Emotional Maturity}

Emotional Maturity is one of the vital components of personality which characterizes Multi-trait non-cognitive psychological concept. According to Walter D. Smitson (1974), Emotional maturity is a process in which the personality is continuously striving for greater sense of emotional health, both Intra-psychically and Intra-personality. Emotional Maturity or stability might be considered as a potential factor in any field of life.

It is a stage, which is very essential in human life. One of the major aims of any good educational programme is to help the learner to gain emotional maturity. Children studying in Xth class do not have much emotional maturity because of their inadequate control over the environment. A mature adult due to the development of his various powers has greater control over his environment. So, he possesses emotional maturity to a greater degree. An emotionally mature person has full control over the expression of his feelings. However, he behaves according to the accepted social values and ideals.

Jersild (1963) says, 'Emotional maturity means the degree to which person has realized his potential for richness of living and has developed his capacity to enjoy things, to relate himself to others, to love and to laugh; his capacity for whole hearted sorrow, when an occasion arises and his capacity to show fear when there is occasion to be frightened, without feeling a need to use a false mask of courage, such as must be assumed by persons afraid to admit that they are afraid'. [1]

According to Crow and Crow (1962), "The emotionally mature or stable individual regardless of his age, is the one who has the ability to overcome tension to disregard certain emotion stimulators that effect the young and view himself objectively, as he evaluates his assets and liabilities and strive towards an improved integration of his thought, his emotional attitude and his overt behaviour. [2]

Mostly, emotional balance' and 'emotional maturity' is taken as synonymous terms. But actually, they are not. Emotional balance emphasizes the value of learning to cope with both pleasant and unpleasant emotions. One can attain emotional maturity without having attained emotional balance although the vice versa is not true. An emotionally balanced person will necessarily be emotionally mature person. Emotional balance is quality of an adult and not a child. Thus, 
emotional maturity is a relative term. It is directly related to age and stage of development of the individual.

\section{Academic Achievement}

Now-a-days the world is becoming more and more competitive. Quality of performance has become the key factor for individual progress especially in adolescent stage. Adolescence is the period of transition from childhood to adulthood. This period has flexibility, because of the individual differences. It is often described as the period of storms and stresses. This is the period from 16 to 18 or 19 years. It is characteristically an important period in the life span, a time of change, a problem age, a time when the individual searches or identifies, a dreaded age, a time of unrealisation and the threshold of adulthood. Adolescent is a period of physical, social, emotional and mental change and development. At present parents that wish their children to climb the ladder of performance to a high level. This desire for high level of achievement puts a lot of pressure on teachers and students, and in general the system of education.

Good (1981) in the Dictionary of Education refers to academic achievement as the knowledge attained or skills developed in the school subjects, usually designated by test scores or marks assigned by the teacher.[3] According to Kohli (1975), academic achievement is the level of proficiency attained in academic work or as formally acquired knowledge in the school subjects which is often represented by percentage of marks obtained by students in examination.[4]

According to Oxford Advanced Learner's Dictionary (2000), achievement is a thing that somebody has done successfully; especially using his/her own effort and skill. From the definitions given above, it may be concluded that academic achievement is the core of wider term 'Educational growth' and perhaps none would deny the importance of academic achievement in child's life. Achievement in the school may be taken to mean any desirable learning that is observed in the students. Since the word desirable implies a value judgment. So, it is obvious that a particular piece of learning may be referred to as achievement or not depends upon whether it is considered desirable or not. Achievement is concerned to a greater extent with the development of knowledge, understanding and acquisition of skills.

\section{REVIEW OF LITERATURE}

\section{Positive correlation between Emotional Maturity \& Academic Achievement}

Dhami (1974) investigated the intelligence, emotional maturity and socioeconomic status as factors indicative of success in scholastic achievement of IX and X class students of age group $14+$ and $15+$ of different categories of students of Punjab and reported a high significant relationship between emotional maturity, intelligence and scholastic achievement of high schools students. The study also reported parent's education, type of house in which family lives, family income and type of reading material has a positive effect on the emotional maturity of the children. [5] 


\section{Emotional Maturity and Academic Achievement among Adolescent Students: A Review of Studies}

Sabapathy (1986) examined the relationship between the variables anxiety, emotional-social maturity, socio-economic status and academic achievement of students. He found emotional maturity was positively and significantly related to achievement in individual subjects and total academic achievement.[6]

Muley Patnam and Vasekar (2003) studied the emotional maturity of school going children of slum and urban areas and the influencing factors. The slum children differ in their emotional maturity from the urban children, which was tested in this study. The sample consists of 120 children, of which 60 were from slum and 60 from urban areas. Significant positive relationship was found between urban children's emotional maturity and their academic performance, chronological age, ordinal position abilities, size and type of family, parenting, general mental ability number of friends as well as their parental age, education and employment while no significant correlation was found between slum children's emotional maturity and their background variables.[7]

Lekhi (2005) in her study on a sample of 939 (male and female) from govt. and private schools of Punjab, found that there is no significant difference in the emotional maturity and emotional intelligence of boys and girls as t-ratio is found to be non-significant. However, on comparing their mean scores, it is observed that boys scored little low (hence more emotionally mature) as compared to girls. But significant differences were found between rural and urban adolescence in their emotional maturity. She also concluded that emotional maturity correlated negative and significantly with intelligence and academic achievement. [8]

Suman (2009) made a study of learning achievement in science of students in secondary schools in relation to their metacognitive skills and emotional competence. The study was conducted over a sample of 500 students of class IX (age between 13 to 15 years) from six secondary schools situated in South West Zone of Delhi. In this study he found that there were significant positive relationship between (i) emotional competence \& learning achievement (ii) metacognitive skills \& learning achievement (iii) emotional competence \& metacognitive skills of the students studying in secondary schools. [9]

Thukral, Praveen and Singh, Surjit (2010) made a study on a social maturity and academic achievement of high school students. The study was conducted over a sample of 400 (200 boys and 200 girls) high school students studying in Xth class in 8 different schools (4 urban and 4 rural) affiliated to CBSE, New Delhi. In his study he found that there existed -significant relationship between social maturity and academic achievement of high school students. No significant differences were observed between boys and girls as well as rural and urban high school students on the basis of their social maturity. [10] 


\section{Emotional Maturity and Academic Achievement among Adolescent Students: A Review of Studies}

A study conducted to examine the role of emotional maturity and emotional intelligence in learning and achievement, on 300 male Intermediate students of Meerut city. Findings reveal that emotional maturity has insignificant effect on learning but significant effect on academic achievement. Emotional intelligence has insignificant effect on learning but significant effect on academic achievement. [11]

In a study on the role of social maturity in academic achievement of high school students it was found that the social maturity contributed the highest in the academic achievement of high school students in a given set of variables. Moreover, the total variance accounted for the variable of social maturity in case of boys was lesser than those of girls and the total sample. The reduced values of partial coefficients of correlation between social maturity and academic achievement indicated the weakness in relationship between social maturity and academic achievement which was more marked in case of girls than the boys and the total sample. Boys and girls as well as rural and urban high school students did not differ significantly in their social maturity. [12]

Education brings about considerable changes in the individual relating to his physical, intellectual and emotional conditions. It becomes the responsibility of everyone concerned with education to prevent failure and wastage and ensure proper academic achievement and success on the part of students. Academic achievement is considered to be a composite criterion and not a unitary one. [13].Emotional maturity as an important factor exerts influence on the academic achievement of students. In this context, it is necessary to study the relationship between academic achievement and emotional maturity of B.Ed. trainees. A person who is able to keep his emotion under control is said to have emotional maturity. It is an ability to tolerate a reasonable amount of frustration (Kaplan and Barar, 2000). Emotional maturity is the process of impulse control through the agency of self. It is a process of readjustment, which is patterned in accordance with the approved expression and repression in their cultures. In the present investigation the marks scored by the B.Ed. trainee's model exam in the University examination have been used as the academic achievement scores. The emotional maturity scale develop by Romapal (1984) was used to assess the emotional maturity level of the students. Descriptive, differential and correlation analysis were computed to analyse the data. It is inferred that a positive and significant relationship exists between academic achievement and emotional maturity.

Malliick Rinku, Singh Archana, Chaturvedi Poonam \& Kumar Narendra (2014), “A Study on Higher Secondary Student's Emotional Maturity and Achievement”. This study found that (i) there is significant difference between male and female higher secondary students with respect to level of emotional maturity. (ii) There is no significant difference between rural and urban higher secondary students with respect to level of emotional maturity. (iii) There is no significant difference between government and aided higher secondary students with respect to level of emotional maturity. (iv) There is significant difference between day scholar and hostel staying 


\section{Emotional Maturity and Academic Achievement among Adolescent Students: A Review of Studies}

higher secondary students with respect to level of emotional maturity and (v) there is significant difference between male and female higher secondary students with respect to level of achievement in economics. [14]

V.Shanmuganathan \& K.Chinnappan (2014) The present study explored the extent to which the Emotional Maturity and Parental Encouragement have the relation with academic achievement among higher secondary course students. The descriptive survey research method was used for the study. In the present study sample of 1000 adolescence (385 boys and 615 girls) were taken by using proportionate stratified random sampling technique. The findings of the study revealed that: (i) there is a significant relationship between the emotional maturity and academic achievement of adolescent students; (ii) there is a significant relationship between the parental encouragement and academic achievement of adolescent students.[15]

Nikhat Yasmin Shafeeq \& Afeefa Thaqib (2015) The aim of the present study is to investigate emotional maturity of secondary school students in relation to academic achievement. For this purpose a sample of 400 students (200 boys and 200 girls) of class IX were taken from 8 schools (4 Government and 4 Private) of Aligarh. For this purpose Emotional Maturity Scale by Dr. Yashvir Singh and Dr. Mahesh Bhargava (1990) and Academic Achievement of the VIII class were used .The study reveals that most of the secondary school students are extremely unstable regarding emotional maturity. The study also reveals that there exist a highly positive correlation between emotional maturity and academic achievement of secondary school students. [16]

\section{Negative correlation between Emotional Maturity \& Academic Achievement}

Kaur, M. (2001) conducted study on 'Emotional maturity of adolescence in relation to intelligence, academic achievement and environmental catalysts' on a sample of 356 adolescence. The findings revealed; (a) Emotional maturity and intelligence were found to be closely related (b) No significant relationship was found between emotional maturity and academic achievement; (c) No significant difference was found in emotional maturity due to area, sex and type of school; (d) Students of government schools were found to be more emotionally mature than those of private schools. [17]

Gakhar S. C. (2003) conducted a study on "Emotional maturity of students at secondary stage: self-concept and academic achievement”. The study used a sample of 200 students of secondary stage, the study revealed: (i) there is significant difference in the emotional maturity of students of government and private schools; (ii) there is significant difference in the emotional maturity of students who are hostellers and day scholars; and (iii) there is significant difference in the emotional maturity of children of working and non-working mothers and the academic achievement on self-concept. It was found a significant negative correlation as found between self-concept and emotional maturity. It was also found negative correlation between academic achievement and emotional maturity. There was significant difference in the emotional maturity

(c) The International Journal of Indian Psychology, ISSN 2348-5396 (e)| ISSN: 2349-3429 (p) | 145 
of boys and girls. It was revealed that there was significant difference in the emotional maturity of students belonging to urban and rural areas and emotional maturity of students of rural areas is more as their mean scores on emotional maturity inventory was less. There was significant difference in the emotional maturity of students who studied in government and private schools. Further, emotional maturity of students of private schools was more as compared to their counterparts due to low mean score on emotional maturity scale. It also showed that there was insignificant difference in the emotional maturity of students who lived in hostels and those who are day scholars. The study also revealed that there was insignificant difference in the emotional maturity of children of working and non-working mothers. [18]

Vikrant Upadhyay \& S.K. Upadgyay (2004) studied “A study of emotional stability and academic achievement of boys and girls at secondary level" at Ph.D. level and concluded their main findings: (i) Boys are significantly emotionally stable than girls, (ii) There is no significant difference between boys and girls in academic achievement. (iii) There is no significant relationship between emotional stability and academic achievement of the students. [19]

Surjit Singh, and Parveen Thukral, (2011) conducted a study on "Emotional Maturity and Academic Achievement of High School Students". The objectives of the study were: (i) To investigate the relationship of emotional maturity with academic Achievement of high school students; and (ii) To see the sex and regional difference on the basis of their emotional maturity. The sample comprised of 400 students of class X, out of them 200 were boys (100 rural and 100 urban) and 200 were girls (100 rural and 100 urban). The sample was collected by using multistage random sampling technique. The tool used was Emotional Maturity Scale (EMS) developed by Singh and Bhargava (1990). The findings of the study were: (i) there is no significant relationship between emotional maturity and academic achievement. (ii) No significant differences were observed between boys and girls and rural and urban students on the basis of their emotional maturity. [20]

\section{METHODOLOGY}

\section{Objective}

- To study the relationship between Emotional Maturity and Academic Achievement of adolescence students.

\section{Hypothesis}

- $\quad$ There would be a significant relationship between Emotional Maturity and Academic Achievement among adolescence Students.

\section{RESULT \& DISCUSSION}

The period of adolescence is of supreme importance in the life of human. It is the period in which a person gets physical, emotional and mental maturity. Adolescence must learn how to cope with psychological stress, handle peer pressure, deal with their emotions, resolve conflicts,

(C) The International Journal of Indian Psychology, ISSN 2348-5396 (e)| ISSN: 2349-3429 (p) | 146 


\section{Emotional Maturity and Academic Achievement among Adolescent Students: A Review of Studies}

build bridges with friends and family, develop self-confidence, safeguard themselves from high pressure marketing strategies, particularly of the alcohol industry, as well as cope with other stresses like academic competition and a hankering for material gains. They need to have good emotional maturity. Everyone has both positive and a negative experience in life. The ability to cope with negative experiences varies greatly from one person to another and, in large part, determines whether people enjoy their lives. Performance in any endeavor is largely contingent upon mental preparation, psychological strength and emotional maturity. Academic achievement has great importance for both the student, and those around him/her. There can be no doubt that it is affected by two broad factors: subjective factors or individual factors and objective factors or environmental factors. The subjective factors are related to the individual himself and the objective factors pertain to the environment of the individual. [21] Thus achievement refers to knowledge and skills gained from experience, an achieved level of expertise or performance in a specific domain.

On the basis of reviews of literature it is clear that there is a significant correlation between Emotional maturity and Academic achievement. A few studies also showed significant relationship between emotional maturity and intelligence as well as significant differences between boys and girls on the basis of their emotional maturity and academic achievement. It has been found that the studies which shows significant relationship between emotional maturity and academic achievement has been conducted in metropolitan cities, private schools, urban students. Parenting style and family environment contribute a lot in their upbringing which help them to become more resilient in during the challenges. Private schools also arrange some workshop related resilience building, skill enhancement, adjustment etc. So that students can grow academically and make better future in the desired field. However, there are a few studies which fail to show any significant relationship between these two variables. There are many factors which play a very important role like - upbringing, demographical area, background, social economic status etc.

\section{Educational Implications}

Now a days the society, the educational institutions, the school, the college, the family are so complex that the students are facing problems in their daily life in relation to their emotional maturity and anxiety, It is the responsibility of the researchers, teachers and parents that the problems should be identified very soon and immediate remedial measures should be provided to the students for the betterment of their lives.

1. A teacher plays important role in developing the personality of a child. He can influence them by his behaviour, thoughts and actions and also enable them to solve their problems which lead to lesser anxiety and better health.

2. The students must be helped to resolve the conflicts which arise due to various problems by understanding them. Students should be encouraged to participate in co-curricular activities which will inculcate the virtues of cooperation, self-discipline and feeling of 


\section{Emotional Maturity and Academic Achievement among Adolescent Students: A Review of Studies}

brotherhood. They should be given the responsibilities in school work so that they develop self-discipline.

3. The curriculum should be constructed keeping in view the needs of students, problems and requirements of every individual.

4. Parents should treat the children in the healthy way. Children should be provided with such an environment which leads to maximum development of positive emotions and minimum development of negative emotions.

5. Parents should be behaving as friends of the child so that child can share feelings and problem. Parents have to guide them to solve their problems themselves, so that they develop as independent adults who can discriminate between right and wrong.

\section{Acknowledgments}

The author appreciates all those who participated in the study and helped to facilitate the research process.

\section{Conflict of Interests}

The author declared no conflict of interests.

\section{REFERENCES}

1. Jersild, A.T. (1963). The Psychology of Adolescents. Toronto: The Macmillan Company.

2. Crow, L.D. and Crow, A. (1962). Child Development and Adjustment. New York: The McMillan Company

3. Good, C. V. (1959). Dictionary of Education, New York: Pleasure Hill Boom Co. Inc.

4. Kohli T. (1975). "Characteristic, Behavioural and Environmental Correlates of Academic Achievement of Over- and Under- Achievers at Different Levels of Intelligence". Unpublished Ph.D. thesis, Department of Education, Punjab University, Chandigarh

5. Dhami G.S. (1974), Intelligence, Emotional Maturity and Socio-Economic status as factors indicative of success in scholastic achievement, Ph.D. Education, Punjab University

6. Sabapthy, T. (1986). "A study of Relationship of Manifest Anxiety, Emotional Maturity of standard Xth students of their Academic Achievement." Fourth Survey of Research in Education (Vol.1) New Delhi, NCERT, 84.

7. Deepa, Muley, Visala, Patnam and jaya, Vasekar (2003) "Emotional maturity of School Going Children of Slum and Urban Areas and the Influencing Factors". Journal of Community guidance and research, 20, 25- 28.

8. Lekhi, V. (2005). "A Study of Emotional Maturity of Adolescents in Relation to Cognitive and Non-Cognitive Variables," Ph.D. Thesis, P.U.Chandigarh.

9. Suman (2009), "A Study of Learning Achievement in Science of Students in Secondary Schools in Relation to their Metacognitive Skills and Emotional Competence”. An Published Theis, Institute of Advanced Studies in Education (IASE), Jamia Millia Islamia.

10. Thukral, Praveen and Singh Surjit (2010), "Social Maturity and Academic Achievement of High School Students”. Canadian Journal of Scientific and Industrial Research, Vol.1, No.1, pp.6-9. 
11. Amit Chaturvedi \& Reena Kumari (2012), "Role of Emotional Maturity and Emotional Intelligence in Learning and Achievement in School Context”. Shaikshik Parisamvad (An International Journal of Education) | 1 SPIJE, ISSN 2231 - 2323 (Print), 2231 - 2404 (Online) Vol.2, No.2, July 2012, pp 1 - 4.

12. Puar, Sujit Singh (2012), "Role of Social Maturity and Academic Achievement of High School Students". International Journal of Education and Psychological Research (IJEPR), ISSn 2279-0179, Vol.1, Issue 1, pp.6-11.

13. Dr.G.Arumugam (2014), "A Study on Academic Achievement and Emotional Maturity of B.Ed. Trainees in Cuddalore District”. International Journal of Modern Research and Reviews, ISSN: 2347 - 8314, Volume 2, Issue 11, pp 497-500, November, 2014.

14. Malliick Rinku, Singh Archana, Chaturvedi Poonam \& Kumar Narendra (2014), “A Study on Higher Secondary Students Emotional Maturity and Achievement”. International Journal of Research \& Development in Technology and Management Science Kalish, ISBN-978-1-63102-445-0, Vol-21, Issue-1.

15. V.Shanmuganathan \& K.Chinnappan (2014), “A Study of the Problems of Adolescents of Higher Secondary Course in Relation to Academic Achievement and Some Selected Psychological Variables”. International Educational E-Journal, \{Quarterly\}, ISSN 22772456, Volume-III, Issue-II, Apr-May-June 2014

16. Nikhat Yasmin Shafeeq \& Afeefa Thaqib (2015), “Comparative Study of Emotional Maturity of Secondary School Students in Relation to Academic Achievement”. The International Journal of Social Sciences and Humanities Invention Volume 2 issue 06 2015 page no.1437-1444 ISSN: 2349-2031.

17. Kaur M. (2001). "A Study of Emotional Maturity of Adolescents in Relation to Intelligence, Academic Achievement and Environment Catalysts”. Ph.D. Thesis, P.U.Chandigarh.

18. Gakhar, S.C. (2003). “A study of Emotional Maturity of student at secondary stage, selfconcept and academic achievement”. Paper published in Journal of Indian Education. Vol.XXIX, No.3, New Delhi: NCERT. Pp 100-106.

19. vikrant, Upadhyay \& S.K. Upadgyay (2004), A study of emotional stability and academic achievement of boys and girls at secondary level\| Indian journal of education research vol 23, No.2, July- December 2004 Page - 41 Education Department University of Allahabad.

20. vikrant, Upadhyay \& S.K. Upadgyay (2004), A study of emotional stability and academic achievement of boys and girls at secondary levell Indian journal of education research vol 23, No.2, July- December 2004 Page - 41 Education Department University of Allahabad.

21. Steinberger, Elizabeth. (1993). Improving Student Achievement. Arlington, Va: American Association of School Administrators.

How to cite this article: M Kumar, R Mishra (2016), Emotional Maturity and Academic Achievement among Adolescent Students: A Review of Studies, International Journal of Indian Psychology, Volume 3, Issue 4, No. 57, ISSN 2348-5396 (e), ISSN: 2349-3429 (p), DIP: 18.01.035/20160304, ISBN: 978-1-365-23993-9 